\title{
A Critical view of Pharmacy Education and Practice in Kenya
}

\author{
Mitchel Otieno Okumu ${ }^{* 1}$, Francis Okumu Ochola ${ }^{2}$, Mary Atieno Onyango ${ }^{3}$ \\ 'Department of Public Health, Pharmacology and Toxicology, Faculty of Veterinary Medicine, University of Nairobi. P. O BOX $29053-00625$ Nairobi, KENYA. \\ 2Department of Pharmacology and Toxicology, Faculty of Medicine, Moi University. P.O BOX 3900-30100 Eldoret, KENYA. \\ ${ }^{3}$ Department of Pharmacology, School of Medicine, Maseno University. P.O BOX 3275-40100 Kisumu, KENYA.
}

Correspondence: Mitchel Otieno Okumu, Department of Public Health, Pharmacology and Toxicology, Faculty of Veterinary Medicine, University of Nairobi, Nairobi, KENYA.

Tel. +254718232255

E-mail: mytchan88@gmail.com

DOI: 10.5530/jyp.2017.9.25

Sir,

The importance of the pharmacy practitioner to the healthcare team in general and to the patient in particular is under serious threat in Kenya. The perception that the exclusive role of the pharmacist is to dispense medication and manage the supply chain of drugs and related commodities underscores the dim view held by the public and other cadres of the healthcare system towards the pharmacy profession. While the rest of the world continues to actively make the practice of pharmacy dynamic, the situation in Kenya has for a good long time remained frustratingly static. Presently, Bachelor of Pharmacy (B. Pharm) is a 5-year program. It is offered in seven institutions namely the University of Nairobi (UoN), Kenyatta University (KU), Jomo Kenyatta University of Agriculture and Technology, Kenya Methodist University (KeMU), Mount Kenya University (MKU) and United States International University (USIU). ${ }^{1}$ However, the curriculum is structured in such a way that clinical pharmacy accounts for a very small part of the program with a year or two being deemed sufficient contact time with this discipline of pharmacy. Moreover, the B. Pharm degree is the minimum pre-requisite for licensure as a pharmacist in the country. ${ }^{1}$ This is at a time when the rest of the developing world is embracing the Doctor of Pharmacy program (PharmD) in a bid to diversify the repertoire, skillset and role of the pharmacist. ${ }^{2}$ There are tell-tale signs that the country is teetering on the brink of lagging behind the rest of the world as far as this noble profession is concerned. The onus of improving the current situation is on the commission for university education (CUE), the pharmacy and poisons board (PPB), the pharmaceutical society of Kenya (PSK), institutions of higher learning and other relevant stakeholders. There is a need to make a concerted effort to not only overhaul the pharmacy curriculum but to also improve the practice of pharmacy.

The Doctor of Pharmacy program (PharmD) is one whose principal focus is patient care. It was first launched in the US as early as the 1960's. ${ }^{3}$ However, the program has endured a treacherous journey before its recognition as an autonomous profession within the field of health. ${ }^{4}$ Nonetheless, once the profession established its footing, the role of a pharmacist metamorphosized from dispensing to clinical intervention. ${ }^{5}$ Eager to tap into this positive outcome, some developing countries have begun adopting the American 'success story' only slightly modifying the curriculum to a level commensurate to their healthcare needs. ${ }^{6}$ The jury is still out as far as what the impact of the program has been in these countries.

The PharmD program in the US comprises of 2 years of foundation units followed by four years (or 3 calendar years) of professional study after which a student is eligible to sit for examinations at state level. Post- professional/graduate study involves either a residency in oncology, paediatrics, geriatrics, critical care or an $\mathrm{MS} / \mathrm{PhD}$ in the core areas of pharmacology, pharmacognosy, Medicinal Chemistry, Pharmaceutics and Pharmaceutical Microbiology. Residency programs are considered as specialities with distinct licensing requirements regulated by the Board of Pharmacy specialities (BPS). ${ }^{7}$

In Kenya, the structure of the pharmacy curriculum seems to appreciate the fact that the level of exposure of undergraduate students to the core areas of clinical pharmacy education is wanting. Cogniscent of this, the Master of Pharmacy in Clinical Pharmacy program (M. Pharm, Clinical Pharmacy) is offered at the University of Nairobi (UoN) as a post-graduate program meant to help students nurture and hone in on clinical skills. ${ }^{8}$ Whether this could be regarded as the equivalent of PharmD is a matter of conjecture. Additionally, foreign universities such as Purdue University and Indiana University have partnered with Moi University school of medicine to train pharmacists in HIV care under the United States-Agency for International Development (USAID) model. ${ }^{9}$ Hence, it is noteworthy that such arrangements points to deep social issues of inadequacy of not only resources but also educational infrastructure. The ripple effect is that very few pharmacists with clinical prowess are available to offset the ever increasing demand for complex clinical pharmacy oriented services. In some countries in Asia, clinical know-how is cultivated by exposing PharmD students to clinical oriented clerkships. A substantial percentage is spent on research into rational drug use and didactic training on clinical pharmacy practice all year round over a 5-year period. In India, before an institution of higher learning is duly registered to offer the PharmD course, it must be affiliated to a 300 bed hospital facility. ${ }^{10}$ This ensures that students get the requisite experience and training they need to tackle complex drug-related problems and carve out a niche' in the healthcare team. Moreover, a culture of research is cultivated early on in the profession. ${ }^{11}$ This is in stark contrast to the situation in Kenya where students have brief spells of contact with clinical pharmacy in the hospital setting over the course of their studies. Moreover, new graduates are expected to undergo a mandatory 6 month supervised internship at a government hospital to principally serve in dispensing medication either to the wards or to outpatients. This culture of retrogressive attitudes is slowly confining the profession to the doldrums.

In conclusion, we opine that;

1. The present curriculum should be modified with the aim of coming up with two parallel degree programs; Bachelor of Pharmaceutical sciences (BSc.PharmSc) and Doctor of Pharmacy (PharmD). The BSc.PharmSc would be tailored for the pharmaceutical industry 
while the PharmD program would cater for the hospital and community pharmacy settings.

2. PharmD/MBA, PharmD/MPH dual degrees should be introduced. Students keen on careers in business or administration would naturally be drawn to the former while those with an interest in epidemiological research would lean towards the latter. Lectures, tutorials and other forms of instruction with a strong research component should be incorporated in the syllabi.

3. The current crop of pharmacists should be exposed to clinical healthcare settings in a bid of ensuring they have first contact with patients rather than the terminal contact as is at present.

4. An academic platform should be created through which Bachelor of Pharmacy graduates can upgrade to Doctor of pharmacy (PharmD) within a reasonable time frame

5. Simulation of medical cases at undergraduate level should be encouraged to promote critical thinking and analysis in the clinical context.

6. There should be an open dialogue to discuss the relevance of the PharmD degree in Kenya

\section{CONFLICT OF INTEREST}

The authors declare no conflict of interest

\section{AUTHORS CONTRIBUTIONS}

Okumu MO- Designed the concept, drafted the manuscript and gave final approval of the version to be published

Ochola FO- Drafted some sections of the article and made critical revisions to the manuscript to ensure intellectual content

Atieno MO- Critically revised the manuscript and assisted in acquisition of some data

\section{ABBREVIATIONS USED}

B. Pharm: Bachelor of Pharmacy; UoN: University o f Nairobi; KU: Kenyatta University; JKUAT: Jomo Kenyatta University of Agriculture and Technology; KeMU: Kenya Methodist University; MKU: Mount Kenya University; USIU: United States International University; PharmD: Doctor of Pharmacy; CuE: Commission for University Education; PPB: Pharmacy and Poisons Board; PSK: Pharmaceutical Society of Kenya; MS: Master of Science; PhD: Doctor of Philosophy; BPS: Board of Pharmacy Specialities; USAID: United Stated Agency for International Development; BSc.PharmSc: Bachelor of Science in Pharmaceutical Sciences; MBA: Master of Business Administration; MPH: Master of Public Health.

\section{REFERENCES}

1. Pharmacy and Poisons Board, PPB (2016). Registered institutions offering Bachelor of Pharmacy degree. Accessed 30/08/2016. Available at http://pharmacyboardkenya.org/?p:528

2. Jamshed S, Zaheer Ud Din Babar, Masood I. The PharmD degree in developing countries (letter). American Journal of Pharmacy Education. 2007; 71 (6)

3. Miller RR. History of Clinical Pharmacy and Clinical Pharmacology. Journal of Clinical Pharmacology. 1981;21:195-7.

4. Syed IA, Mohamed AAH. The controversy of PharmD degree. American Journal of Pharmacy Education. 2008;72(3):71.

5. Hepler CD, Strand LM. Opportunities and responsibilities in pharmaceutical care. Am J Hosp Pharm. 1990;47(3):533-43.

6. Amir M. The Aftereffects of Implementing the PharmD Degree in Developing Countries. Am J Pharm Educ. 2011;75(6):124.

7. American College of Clinical Pharmacy (ACCP). Career opportunities in clinical pharmacy. Available at http://www.accp.com/stunet/compass/career.aspx. Accessed on 30/08/2016

8. Ikoni JO, Titus MK, Onesmus WG, Julius WM. Development of pharmacy education in Kenyan universities to date. African Journal of Pharmacy and Pharmacology. Academic Journals. 2016;10(18)385-92.

9. Schellhase EM, Miller ML, Ogallow, Pastakia SD (2013). An elective pharmaceutical care course to prepare students for an advanced pharmacy practice experience in Kenya.

10. www.pci.nic.in/For colleges.aspx. Accessed on 30/08/2016

11. Begum R, Niazi NS. What I want for Pakistani pharmacy graduates, recommendations from personal experience. Arch Pharma Pract. 2015;6:97-9. 